\title{
Goal Activation, Expectations, and the Placebo Effect
}

\author{
Andrew L. Geers, Paul E. Weiland, \\ Kristin Kosbab, and Sarah J. Landry \\ University of Toledo
}

\author{
Suzanne G. Helfer \\ Adrian College
}

\begin{abstract}
Motivational factors receive little attention in current theories of the placebo effect. Reasons for this position are reviewed, and an argument is made for reconsidering the influence of motivation on the placebo effect. The authors hypothesize that nonconscious goals alter reactions to a placebo expectation. Specifically, the authors predict that the placebo effect is most likely to occur when individuals have a goal that can be fulfilled by confirmation of the placebo expectation. The authors tested this notion in 5 experiments. The results demonstrate the role of motivation in the placebo effect across a variety of symptom domains and via 4 different goal activation techniques. Moreover, this moderating effect occurred for both positive and negative placebo expectations, across different placebo effect measures, and in brief laboratory experiments as well as in lengthier studies. It is argued that theories regarding the placebo effect should incorporate motivational factors.
\end{abstract}

Keywords: expectations, goals, health, placebo effect

The word placebo entered the English language around the 13th century (Shapiro, 1964). The word was translated from Vulgate Latin, meaning to please, to give pleasure, to suit, and to satisfy (Lasagna, 1986; Lewis, 1953; Shapiro \& Shapiro, 1997). Early medical definitions include "a medication given to please" (Dorland, 1901) and "medicines prescribed more to please the patient than for its therapeutic effectiveness" (Fox, 1803).

These initial conceptualizations of a placebo clearly possess a strong motivational element. That is, a placebo was originally viewed as a medication or treatment that was administered to fulfill a need or desire of the patient. In contrast, most recent reviews and research articles on the placebo effect either ignore or discount the potential impact that motives can have on placebo responding (e.g., Ader, 1997; Amanzio \& Benedetti, 1999; Bienenfeld, Frishman, \& Glasser, 1996; Kienle \& Kiene, 1996; Kirsch, 1997; Montgomery \& Kirsch, 1996; Ross \& Olson, 1982; Stewart-Williams \& Podd, 2004). The aim of this article is to reintroduce motivational features to the theory of the placebo effect. We begin by presenting a brief review of the relevant literature and discussing the dominant theoretical perspectives of the placebo effect. Next, we present a model of placebo responding based on recent goal activation research. We then report five studies conducted to assess this motivationally oriented account.

Andrew L. Geers, Paul E. Weiland, Kristin Kosbab, and Sarah J. Landry, Department of Psychology, University of Toledo; Suzanne G. Helfer, Department of Psychology, Adrian College.

We thank Sarah Boyd, Oscar Garza, Katie Graham, Shannon Holleran, Steven Noel, Theresa Triftshouser, and Justin Wellman for their assistance with various aspects of this research.

Correspondence concerning this article should be addressed to Andrew L. Geers, Department of Psychology, University of Toledo, Toledo, OH 43606-3390. E-mail: ageers@utnet.utoledo.edu

\section{The Placebo Effect}

What is the placebo effect? Although a wide array of definitions currently exist (see Brody, 1985; Kienle \& Kiene, 1996; Kirsch, 1999; Moerman, 2002; Shapiro \& Shapiro, 1997; Spiro, 1986; Vase, Riley, \& Price, 2002), in the present article we define it as the physiological or psychological response to an inert substance or procedure (Stewart-Williams, 2004). Important aspects of this definition are that the placebo effect is not limited to particular individuals (e.g., patient or nonpatient samples), types of treatments, or either psychological or physiological dependent measures (Kirsch \& Weixel, 1988; Stewart-Williams \& Podd, 2004).

Medical scholars have argued that, until the early part of the 20th century, the benefits of prescribed remedies were largely placebo effects (Lasagna, 1986; Major, 1954; Shapiro \& Shapiro, 1997). Although we are now in the age of modern medicine, it is still possible that the success of many drugs and therapeutic treatments are, in part, the result of placebo responding (Andrews, 2001; Bierman, 2000; Brody \& Brody, 2000; Enserink, 1999; Peters, 2001). Consistent with this perspective are the hundreds of studies over the last half century reporting placebo effects in virtually all areas of patient care (for reviews, see Bienenfeld et al., 1996; Jospe, 1978; Shapiro \& Morris, 1978; Spiro, 1986; White, Tursky, \& Schwartz, 1985). Moreover, several recent metaanalyses indicate that the impact of most antidepressant medications is almost entirely due to the placebo effect (e.g., Kirsch \& Sapirstein, 1998).

Further indication of the importance of this phenomenon comes from the medical community, in which the placebo control has become a must for rigorous investigations of new treatments and therapies (i.e., the double-blind, randomized, placebo-controlled clinical trial). It has been estimated that more placebos have been dispensed to research participants than any other experimental drug or medical treatment (Kirsch \& Sapirstein, 1998). Given the abundance of studies that have included placebo conditions, one might expect that the causes of the placebo effect are well understood. Surprisingly, relatively little research has been conducted to 
directly study this effect (Ader, 2000; Ernst \& Resch, 1995; Kienle \& Kiene, 1997). As noted by Kirsch and Sapirstein (1998), "although almost everyone controls for placebo effects, almost no one evaluates them" (p. 1). Less than $4 \%$ of the studies that include placebo conditions also include a no-placebo control group to evaluate the effect of the placebo itself (Ernst \& Resch, 1995; Fisher, 2000). In most studies designed to assess the effectiveness of medical treatments, the placebo group is usually compared with an active-treatment group and is not compared with a no-placebo control group.

\section{Theoretical Perspectives on the Placebo Effect}

A great deal of debate exists regarding the mechanisms underlying the placebo effect (Harrington, 1997; Jospe, 1978; Montgomery \& Kirsch, 1996; Peters, 2001; Stewart-Williams, 2004; White et al., 1985). The main theoretical approaches to the placebo effect can generally be categorized as a classical conditioning view, an expectancy view, and a motivational view. It is interesting that these three views have been considered competing explanations and that, until recently, there have been few efforts at conceptual integrations (Price \& Fields, 1997; Stewart-Williams \& Podd, 2004). The majority of the experiments in this area attempt to differentiate between the first two theoretical perspectives and overlook the possible role of motives in placebo responding (e.g., Amanzio \& Benedetti, 1999; de Jong, van Baast, Arntz, \& Merkelbach, 1996).

\section{The Classical Conditioning Perspective}

According to the classical conditioning approach, active medications are the unconditioned stimuli, the methods or techniques used to administer treatments are the conditioned stimuli, and the placebo effect is the conditioned response (Voudouris, Peck, \& Coleman, 1985; Wickramasekera, 1985). Studies testing this perspective have found classical conditioning can account for the placebo effect in both human and nonhuman animals (e.g., Flaten \& Blumenthal, 1999; Hernstein, 1962; Voudouris et al., 1985).

Numerous problems arise, however, when one accounts for the placebo effect solely through traditional classical conditioning (Hróbjartsson, 1996; Kirsch, 1991, 1997). For example, classical conditioning cannot explain why prior experience with the active drug often does not increase placebo effects (Rickels, Lipman, \& Raab, 1966). Such problems have prompted the use of a more cognitive interpretation of classical conditioning effects (Kirsch, 1991; Stewart-Williams \& Podd, 2004). Essentially, it has been argued that classical conditioning results in the acquisition of a placebo expectancy (Kirsch, 1997; Price et al., 1999). Thus, to some theorists, the classical conditioning view can be seen as a special case of the expectancy view (Kirsch, 1997).

\section{The Expectancy Perspective}

An expectation is a belief about the probabilities associated with a future state of affairs (Olson, Roese, \& Zanna, 1996). The expectancy approach holds that the placebo effect is driven by anticipation that a treatment will result in a particular outcome (Bootzin, 1985; Kirsch, 1999; Stewart-Williams \& Podd, 2004).
Thus, simply put, expecting the suggested reaction is said to lead to the generation of that reaction.

Although data from a wide array of studies point to the influence of expectations on placebo responding, there remain several unresolved issues. First, expectations do not always lead to placebo effects in either correlational or experimental studies (e.g., Hammersley, Finnigan, \& Millar, 1998; Laska \& Sunshine, 1973; Walach, Schmidt, Dirhold, \& Nosch, 2002). Second, the mechanisms by which expectations produce the placebo effect have not been clearly determined (Olson et al., 1996; Stewart-Williams \& Podd, 2004). The expectancy framework that has received the most attention in the placebo literature is that of response expectancy theory (Kirsch, 1997, 1999). According to this framework, a response expectancy is one's anticipated automatic reaction to situational and behavioral cues. Response expectancies are believed to be directly self-confirming (Kirsch, 1997). That is, somatic information is said to be ambiguous, and the boundary between the expectancy and the experience breaks down so that "the perception is not just of the experience, it is the experience" (Kirsch, 1999, p. 6). From a response expectancy view, a placebo response is an immediate and unmediated consequence of the expectation. In contrast to this immediacy hypothesis, however, are the results of studies indicating that the effects of placebo and placebo-like expectations are determined by factors such as attentional focus and causal attributions (J. W. Duncan \& Laird, 1980; Geers \& Lassiter, 1999; Gibbons \& Gaeddert, 1984; Ross \& Olson, 1981).

\section{The Motivational Perspective}

Motivational explanations have typically considered the placebo effect to be an outcome of one's desire to feel better or to feel reduced anxiety (e.g., Plotkin, 1985; Price \& Fields, 1997; Price et al., 1999). Some theorists (Jospe, 1978; Kienle \& Kiene, 1997; Margo, 1999) have argued that the placebo effect may be due to an individual's desire to cooperate with the experimenter or health care professional (i.e., demand characteristics; Orne, 1962), and others have argued that self-enhancing motives alter placebo responding (Gibbons \& Gaeddert, 1984).

Currently, few data are available regarding the role of motives in placebo responding (Price \& Fields, 1997). The data that do exist, however, provide preliminary support. For example, in one experiment, Jensen and Karoly (1991) gave participants placebo pills that were said to have a sedating effect and manipulated participants' desire to feel such effects. This manipulation entailed telling participants that individuals who react to the pills have either positive or more negative personality characteristics. Jensen and Karoly found greater placebo responding in the positive personality condition. However, it is possible that the results of this study reflect self-presentational biases rather than changes in symptom perception. In a more recent experiment, Price et al. (1999) tested the role of expectations and motives on the effectiveness of a topical placebo analgesic during a thermal pain task. This study found an effect of the expectation manipulation but no effect of the motivation manipulation. To manipulate their motivation, participants were provided different information regarding the intensity of the pain they would experience. Specifically, half the participants were told that they would be experiencing many extremely painful trials, whereas the others were told that they 
would be experiencing mildly painful trials. The researchers anticipated that the participants who were informed they would be feeling more pain would have the greatest desire to experience the benefits of a placebo analgesic. Unfortunately, this motivation manipulation is likely confounded with a number of other factors that could have altered its effectiveness, such as expectations, moods, and a sense of helplessness. Hence, the motivational approach necessitates a more thorough investigation.

\section{A Goal-Activation Model of the Placebo Effect}

Currently, no motivationally oriented placebo effect framework exists that can guide research on this topic. In an attempt to infuse motivational variables into the research on the placebo effect, we take a self-regulatory approach (Baumeister \& Vohs, 2004; Cameron \& Leventhal, 2003; Carver \& Scheier, 1981, 1998; Miller, Galanter, \& Pribram, 1960; Norman \& Shallice, 1986). Selfregulation refers to one's attempts to alter or steer thoughts and responses in an effort to achieve a goal. Following research and theory on nonconscious goals (Bargh, 1990, 1997; Freud, 1901/ 1965; Jastrow, 1906; Moskowitz, 2002; Shah, Kruglanski, \& Friedman, 2003), we contend that goal activation and goal pursuit often occur outside of conscious awareness. Thus, situational cues can automatically activate nonconscious goals that operate to guide attention, behavior, and cognition without an individual's awareness (Chartrand \& Bargh, 1996; Shah \& Kruglanski, 2003; Wegner, Fuller, \& Sparrow, 2003). In a typical medical scenario, for example, the goal to cooperate could be activated nonconsciously by the presence of physicians, medical surroundings, or medical devices. This goal, in turn, would alter an individual's thoughts, attention, and behavior (cf. Aarts, Gollwitzer, \& Hassin, 2004; Bargh, 1997; Moskowitz, 2002). Also, consistent with Bargh, Gollwitzer, Lee-Chai, Barndollar, and Tröetschel (2001), we believe that

nonconsciously activated goals will cause the same attention to and processing of goal-relevant environmental information and show the same qualities of persistence over time toward the desired end state, and of overcoming obstacles in the way, as will consciously set goals. (p. 1015)

We hypothesize that to predict placebo responding, one must jointly consider the role of goals and expectations (cf. Harris, 1990; Hilton \& Darley, 1991; Neuberg, 1996; Snyder, 1992). Our view is that although expectations are an important determinant of the placebo effect, an individual's currently active goal drives the extent to which the placebo expectation affects somatic experience. If a compatible goal is associated with the placebo expectation, then an individual will extensively engage in processing and behavioral strategies that are likely to yield a placebo effect. We argue that in placebo scenarios, confirming the particular treatment expectation becomes the most salient means by which a goal such as to cooperate or to feel better can be attained (cf. Aarts \& Dijksterhuis, 2000; Hassin \& Bargh, 2001; Shah \& Kruglanski, 2003). This is analogous to other nonconscious goal studies in which participants are primed with a goal and are then given the means to attain this goal. For example, participants may be primed with the goal to achieve and then given a performance task that becomes the means to fulfill the achievement goal (Bargh et al., 2001).
In contrast, if this functional relation is not forged between a goal and the placebo expectation, the expectation should have considerably less influence on one's somatic experience (cf. Shah \& Kruglanski, 2003). When an individual has either no goal or a placebo-incompatible goal, the placebo expectation will not strongly impact placebo responding. Without the activation of a compatible goal, the expectation is more likely to be discarded or given lower priority in self-regulation and future cognitive processing (Kunda \& Spencer, 2003; Neuberg, 1996).

How do goals moderate the placebo effect? Similar to response expectancy theory, we contend that physical sensations and somatic experiences can be vague, diffuse, nonspecific, and often in a state of fluctuation (Cioffi, 1991; Pennebaker \& Skelton, 1981; Russell, 2003). Thus, like ambiguous information in our external environment, our perceptions of internal sensations can be altered by subjective factors such as expectancies and contextual cues (Anderson \& Pennebaker, 1980; Schachter, 1964). We further contend that expectation effects are not immediate and unmediated but instead occur primarily when one holds a placebo-compatible goal directing cognitive processing and behavior toward the confirmation of a placebo expectation. Finally, we predict that goals direct individuals to confirm a specific placebo expectation instead of a global reduction or increase in the amount of symptoms they perceive (cf. Montgomery \& Kirsch, 1996).

This goal activation view was designed to handle the typical criticisms leveled against the motivational perspective. For example, it has been argued that a motivational perspective cannot account for a negative placebo effect (Stewart-Williams, 2004). That is, because the placebo effect can occur with negative as well as positive symptoms, a single motive, such as a desire to feel better, cannot be the cause. However, the current goal activation viewpoint is not limited to one goal, such as to feel better. Instead, we contend that a broad assortment of goals (cf. Bargh, 1990; Carver \& Scheier, 1998) can be activated consciously and nonconsciously and that some of these goals may be compatible with an expectation to feel negative symptoms. For example, a patient could have a nonconscious goal for increased attention from others. This goal can be compatible with a negative placebo expectation, such as the expectation for unpleasant side effects of a medication. Nonconscious goals in combination with a negative placebo expectation could cause patients to interpret more sensations as negative symptoms.

A second criticism used to discount motivational views is that, according to motivational approaches, participants are not actually experiencing genuine placebo reactions but are "faking it" on self-report measures. This criticism takes the stance that motives, such as to cooperate, are always conscious. However, as mentioned above, our view is that motives altering the placebo response are often outside of one's conscious awareness. This criticism also suggests that, although motivational theories can explain changes on self-report measures, they cannot account for placebo effects found on more objective criteria. In addressing this issue, we first note that, because many placebo studies have not incorporated a no-placebo control condition, it is often unclear what proportion of these effects is due to the placebo effect and what proportion is due to other factors, such as spontaneous remission or regression to the mean (Ernst \& Resch, 1995; Kienle \& Kiene, 1997; McDonald, Mazzuca, \& McCabe, 1983). Indeed, the strongest evidence for the placebo effect is found on more 
subjective measures, such as those used in research on the reduction of pain and depression (Hróbjartsson \& Gotzsche, 2001; Kirsch \& Sapirstein, 1998; Vase et al., 2002). However, a small number of experiments have found the placebo effect on less subjective measures, such as blood pressure readings (e.g., Kirsch $\&$ Weixel, 1988). From our view, these effects can be the result of the combined role of placebo expectations and a compatible goal. For example, the goal to cooperate could be associated with a placebo expectation that causes individuals to alter their thoughts and actions, which leads to a change in stress level (cf. Gross, 1998). Psychological variables such as stress and anxiety can alter physiological reactions, and we expect that these adjustments can lead to placebo-consistent physiological changes (Bierman, 2000; Brody \& Brody, 2000; Lazarus \& Folkman, 1984). Thus, this goal perspective can account for variations on both subjective and objective measures.

\section{The Present Research}

Five studies were conducted to assess the merit of a goal activation explanation for the placebo effect. The main hypothesis was that placebo expectations would be more likely to produce effects when participants held a placebo-compatible goal. In these studies, we focused on one motive, that of cooperation. This motive was chosen for two main reasons. First, the motive to cooperate has been discussed previously as a potential cause of the placebo effect (e.g., Jospe, 1978; Ross \& Olson, 1982). Second, prior studies have successfully manipulated cooperation using nonconscious primes (Bargh et al., 2001; Macrae \& Johnston, 1998).

\section{Study 1}

Study 1 provides an initial test of our hypothesis that nonconscious goals moderate the effects of placebo expectations. In this experiment, participants listened to a piece of music and evaluated how they felt. One group of participants was given no expectation regarding how this music might influence their feeling states, whereas the other participants were given the expectation that the music would make them feel better. In addition to this placeboexpectation manipulation, we also manipulated the nonconscious goals held by some of the placebo-expectation participants. Specifically, one group of participants was primed to hold a nonconscious goal for cooperation, whereas another group was not primed with a goal. We predicted that the participants primed with the goal of cooperation would report having the strongest reactions to the placebo treatment. Additionally, we included another group of participants who were primed to hold a nonconscious goal for independence. This final condition was added to determine whether any goal would strengthen placebo-expectation effects or whether only goals that could be satiated through confirmation of a placebo expectation would strengthen these effects. We predicted that, because the goal of independence would not be satisfied by confirmation of the placebo expectation in this study, this goal would not increase placebo responding.

\section{Method}

Participants and design. Twenty-one female and 24 male psychology undergraduates participated in return for partial course credit. Participants were randomly assigned to one of four experimental conditions (no expectation/no prime, placebo expectation/no prime, placebo expectation/cooperation prime, and placebo expectation/independent prime). Participants also completed an affect measure at the beginning and end of the experiment, which resulted in a 2 (time) $\times 4$ (condition) mixed design.

Procedure. On arrival, participants were informed that they would be taking part in two ostensibly unrelated experiments. Before beginning the first experiment, participants were asked to complete a brief affect questionnaire. Embedded in the questionnaire were five critical items relevant to the present study. Specifically, participants rated how much of the following states they currently felt: happy, headachy, cheerful, peaceful, and energetic. Responses to these items ranged from 1 (not at all) to 7 (very much) and were reverse scored when necessary and averaged together to create a gauge of participants' pretreatment affect.

Next, participants were told they were to begin the first study, which was said to be a psycholinguistic task being developed by another researcher. This was actually a 20 -item version of the Scrambled Sentence Test (Chartrand \& Bargh, 1996; Srull \& Wyer, 1979), which has been used in numerous studies to prime nonconscious goals. For this task, participants are presented with strings of five scrambled words and are asked to create a grammatically correct sentence using only four of the five words provided. Of the 20 scrambled word items, 16 contained words that differed depending on participants' experimental condition. In the cooperationprime condition, these words were chosen to prime participants for the goal of cooperation (e.g., helpful, assist, cooperate), whereas the words in the neutral-prime condition were unrelated to cooperation (e.g., begin, look, understood). In the independent-prime condition, the words were chosen to prime participants for independence (e.g., independence, assert, stubborn). The experimenter was unaware of participants' prime condition.

After the priming task, the experimenter described the second experiment. Participants in the no-placebo condition were simply asked to evaluate how the music made them feel. Participants given the placebo expectation were told that they were to listen to a piece of music that had been scientifically developed by neuropsychologists to increase positive feelings and energy levels and to reduce headaches. It was said that these effects would occur because the music selection incorporated certain notes and musical patterns that unconsciously activate the precise regions of the brain that regulate pain and pleasure sensations. Participants were further told that the music piece was currently being examined by the experimenter in preparation for a large-scale therapeutic treatment study.

At this point, all participants were asked to close their eyes and to listen to a piece of music that was approximately $4 \mathrm{~min}$ in duration. The piece was Hop (2), an excerpt from a larger composition by Paul Lansky (1994, track 9). This piece was selected because pilot data revealed that it did not evoke strong affective reactions and the high-pitched electronic tones used in the composition fit well with the cover story. When the music ended, participants were instructed to open their eyes and take several deep breaths and then were given the affect measure from the beginning of the study. Responses to the five primary affect items were reverse scored when needed and averaged together to create our dependent measure $(\alpha=.72)$. Higher scores on both this and the baseline affect measure equate to greater placebo-consistent responding. At the end of the study, participants completed a funnel debriefing (see Bargh \& Chartrand, 2000). None of the participants reported any suspicion of the priming task or awareness that it was related to the subsequent experimental situation.

\section{Results}

Means on the affect indices for each condition are displayed in Table 1 . To test our hypotheses, we submitted the affect scores to a 2 (time) $\times 4$ (condition) mixed analysis of variance (ANOVA). This ANOVA yielded only the anticipated interaction, $F(3,41)=$ 5.17, $p=.004, \eta_{p}^{2}=.27$. To investigate this interaction, we performed simple contrasts on the change in participants' affect. 
Table 1

Pretest and Posttest Means on the Affect Index for Study 1

\begin{tabular}{lcccc}
\hline Test & $\begin{array}{c}\text { No expectation/ } \\
\text { no prime }\end{array}$ & $\begin{array}{c}\text { Expectation/ } \\
\text { no prime }\end{array}$ & $\begin{array}{c}\text { Expectation/ } \\
\text { cooperation } \\
\text { prime }\end{array}$ & $\begin{array}{c}\text { Expectation/ } \\
\text { independent } \\
\text { prime }\end{array}$ \\
\hline Pretest & 5.09 & 4.64 & 4.61 & 5.07 \\
Posttest & 4.49 & 4.46 & 5.12 & 4.88 \\
\hline
\end{tabular}

Note. Higher pretest and posttest scores indicate more positive affect.

Specifically, we computed change scores by subtracting premusic scores from postmusic scores. Higher numbers on the resulting affect index indicate increased placebo-consistent responding. The first contrast compared the change in affect of participants in the no-expectation/no-prime condition $(M$ change $=-0.60)$ with those in the placebo-expectation/no-prime condition ( $M$ change $=$ $-0.18)$. This contrast found no significant difference between these two groups $(p=.20)$. Thus, when participants were not primed with a goal, no placebo effect emerged. A second contrast compared the change in affect of the no-expectation/no-prime participants with that of the placebo-expectation/cooperationprime participants $(M$ change $=0.51)$. This test was significant, $t(41)=3.76, p=.001, d=1.56$. A third contrast, comparing the responses for the participants in the placebo-expectation/no-prime condition with the responses from the placebo-expectation/ cooperation-prime participants, also yielded a significant effect, $t(41)=2.33, p=.03, d=0.93$. Taken together, these tests indicate that the placebo effect was more likely to occur when participants were primed with the goal of cooperation. A final set of comparisons, between the no-expectation/no-prime participants and the placebo-expectation/independent-prime participants $(M$ change $=-0.19$ ) and between the placebo-expectation/no-prime participants and the placebo-expectation/independent-prime participants, yielded no significant effects ( $p s>.15$ ). These two final comparisons indicate that not all goals increase placebo responding.

\section{Discussion}

The results of Study 1 provide the first evidence that nonconscious goals moderate the effects of placebo expectations. The data are consistent with the hypothesis that the placebo effect is most likely when individuals have activated a goal that they can satisfy by responding in a manner consistent with a placebo expectation.

The results from the independent-goal condition suggest that priming a goal does not always increase placebo responding. On the basis of our prior reasoning, one might have expected that the independent-prime participants would report significantly fewer placebo-consistent symptoms than the expectation/no-prime participants. However, there were no differences between these conditions. Yet this obtained pattern of results is consistent with earlier findings that people primed with conformity goals conform more than control participants, whereas people primed with nonconformity goals do not differ from control participants (Dijksterhuis \& van Knippenberg, 1998; Epley \& Gilovich, 1999). Although multiple explanations for this pattern of results exist, a simple one is that individuals act more on conformity than on nonconformity goals in an experimental context (cf. Aarts et al., 2004).

\section{Study 2}

Although Study 1 provides preliminary data indicating that goals moderate the effects of placebo expectations on placebo responding, many questions remain unanswered. Study 2 was conducted in an attempt to address four of these questions. First, the effects in Study 1 were obtained in a brief laboratory context. This design is ideal to determine whether such a moderating effect exists because of the highly controlled nature of the laboratory setting. Also, the brief laboratory-based design is similar to those used in most goal-priming studies (e.g., Chartrand \& Bargh, 1996) and to most controlled placebo experiments (e.g., Geers, Helfer, Kosbab, Weiland, \& Landry, 2005; Montgomery \& Kirsch, 1996). However, if nonconscious goals, such as those evoked by environmental cues in a research laboratory or doctor's office, are important in producing the placebo effect, then we should see these effects over a longer span of time and in other settings. At the moment, there are few data on these issues, but prior research has found that goal primes can alter responses outside of the laboratory (Fitzsimons \& Bargh, 2003). Also, Bargh et al. (2001) found that the effects of goal primes become stronger over time if the goal remains unsatiated. Taken together, these data suggest that goal primes may influence placebo expectations in producing the placebo effect in a nonlaboratory context and over a longer span of time. In Study 2, we explore these issues by having the placebo treatment occur outside of the laboratory and by collecting symptom reports a day later.

A second goal of Study 2 is to generalize the findings of Study 1 to a different kind of symptomatology. In Study 1 we examined participants' positive feelings elicited by a piece of music, whereas in Study 2 we examine participants' reactions to a placebo sleep therapy that purportedly improves the quality of one's sleep. If the present model of placebo responding is viable, we would anticipate that goals moderate expectancy effects in many different domains of symptomatology and types of medical treatments.

A third goal of Study 2 is to extrapolate the results of Study 1 to goal-priming techniques other than the Scrambled Sentence Test. If our present hypotheses are correct, we should find the same moderating effect using multiple goal-priming techniques. To this end, in Study 2 we used three different goal activation techniques.

A fourth goal of Study 2 is to explore the temporal relation between goal activation and placebo expectations. In Study 1, the goal of cooperation was activated prior to the placebo-expectation manipulation. In many medical and research situations, goals are likely activated before a placebo expectation is acquired. However, we suspect that goals can be activated simultaneously or subsequently to an expectation manipulation and still alter the effectiveness of a placebo. As long as a compatible goal becomes associated with the placebo expectation, we should find that goals moderate the effect of the expectation (cf. Kunda \& Spencer, 2003). To test this subsidiary hypothesis, we included one goal-prime condition in Study 2 in which the goal was activated significantly later than the administration of the placebo expectation. 


\section{Method}

Participants and design. Eighty-three female and 36 male psychology undergraduates participated (in small groups) in return for partial course credit. Data from 9 additional participants who began the study are not included in the present analyses. Three failed to complete the two-session study. Two others reported that they did not complete the take-home portion of the study as required. One participant was a work colleague of the undergraduate experimenter. Finally, 3 participants were suspicious of our more explicit goal-priming manipulation and were excluded. The results were virtually identical when the excluded participants remained in the data set.

Participants were randomly assigned to one of six conditions: (a) notreatment control, (b) treatment with no expectation, (c) treatment and a placebo expectation, (d-f) treatment, a placebo expectation, and one of three cooperation-goal primes. Participants completed a quality of sleep measure during two study sessions, which resulted in a 2 (time) $\times 6$ (condition) mixed design.

Procedure. Participants signed up for a study on daily behavior for which they were required to attend two experimental sessions on consecutive weekdays. In the first session, participants completed a survey packet that included a variety of questions about their health and their typical daily behavior (e.g., the amount of TV they watched, how many fruits and vegetables they ate). Embedded in this general questionnaire were a variety of questions regarding participants' sleep schedule and their perception of the quality of their sleep and energy level. These questions included, "How peaceful was your sleep last night?" "How comfortably did you sleep last night?" "How soundly did you sleep last night?" "How would you rate your quality of sleep last night?" and "How relaxed did you feel this morning?" All of these items were rated on 7-point scales, with higher numbers equating to better sleep. We averaged reponses to the five critical items to create a baseline sleep index.

At this point, the procedure differed depending on participants' experimental condition. The first condition, the no-treatment control condition, served as one of two control groups in the experiment. In this condition, after completing the questionnaire packet, participants read and evaluated one written page of information that was said to be for another experimenter. They were asked to check the grammar and spelling used in the passage. The passage was a description of the use of flour in baking adapted from the Larousse Gastronomique cookbook (Lang, 1988). This passage was a control for a condition in which we had participants read a passage of similar length as one of the goal manipulations. When participants finished reading the passage, they were dismissed from the study and reminded to come back the next day. In the second session, participants completed another packet of questionnaires that had our five critical sleep questions embedded in the packet. All participants in the study completed this questionnaire, and we averaged scores on the five sleep items together to form our main dependent measure $(\alpha=.90)$.

In a second control condition, the no-expectation condition, participants also read the one-page passage about flour. Afterward, they were informed that the experimenter was interested in the thoughts people have before falling asleep. These participants were further told that, for this study, they were to go home that evening and spend $10 \mathrm{~min}$ writing down all of their thoughts right before they went to bed. The importance of completing this procedure exactly as instructed that evening was stressed to the participants. Then they were given a booklet to take home with them that evening in which to write down their thoughts. The booklet contained a page instructing participants to prepare for bed before beginning the task (i.e., complete all bedtime rituals, e.g., brushing their teeth). Finally, participants were asked to bring the packet back with them to the second session. In the second session, participants handed in their sleep booklet and completed the 2nd-day dependent measure packet. Thus, the main difference between this condition and the no-treatment condition was that participants in this condition spent 10 min completing a writing task before they went to bed. Participants returned their packet to verify that they did indeed complete this task. They also answered a few confidential questions asking whether they had done the task before bed as they were instructed. As mentioned above, 2 participants in the study reported not completing the task as requested.

The third condition, the placebo-expectation condition, was the same as the no-expectation condition, except for one important difference. These participants were not told that the experimenter was interested in the thoughts people have right before bed. Instead, participants in this condition were told that the experimenter was interested in sleep therapy and that the writing task was a powerful new mental relaxation technique that she believed helped people organize their thoughts before bed. Participants were informed that this therapy relaxes people and improves their quality of sleep. The only other difference between this group and the noexpectation condition was that the instructions on the sleep packet given to these participants described the writing task as a sleep-therapy technique. The procedures used in this condition were followed in the final three conditions, with the exception that in the subsequent conditions we attempted to activate the goal of cooperation.

The fourth experimental condition, the story-prime condition, was the same as the placebo-expectation condition except that instead of reading the passage about the use of flour in baking, these participants read a passage of the same length about a man who helped someone in need. The passage describes how a man driving to work witnesses a car accident and assists the victim of the accident until more help arrives. We used this story to prime participants for the goal of cooperation. Prior research has successfully used this type of goal-priming technique (see Bargh \& Chartrand, 2000), and our pilot testing found that this technique successfully evoked the concept of cooperation. ${ }^{1}$ It should be noted that in all of the other experimental conditions, the description about baking with flour was used as a control for this passage. Also, the experimenter was blind to which passage participants were given to evaluate.

The fifth experimental condition, the evening-prime condition, was also the same as the placebo-expectation condition except for one detail. Specifically, the sleep booklet that participants took home with them had one additional instruction sheet that they were to read right before beginning the sleep therapy. This sheet simply asked participants to check to be sure their packet contained all of the materials that it should and to return the packet during the second experimental session. Embedded in this instruction sheet were 10 words to prime participants for the goal of cooperation (e.g., cooperation, volunteer, aid). This condition was included to test whether a goal activated after a placebo-expectation manipulation could increase placebo responding.

The sixth experimental condition, the cell phone condition, was also the same as the placebo-expectation condition except for one element. In this condition, we tried to activate the goal of cooperation in a more overt fashion than in our other conditions. Specifically, in this condition the experimenter set her cellular telephone to ring just when the participants were about to finish the control passage. The experimenter acted surprised and pretended to begin a conversation with her mother. The experimenter left the room and spoke on the telephone right outside the door, where she could be heard by the participants. She followed a scripted conversation in which she remarked, among filler comments, that she was running her research study, that she hoped it worked, and that she needed the partici-

${ }^{1}$ To pilot test this priming material, we created various cooperationrelated passages and asked students to read them over, ostensibly to look for grammatical errors. After reading a passage, students rated how they felt on various attributes, including cooperativeness. In piloting the present cooperation and control passages, we found that participants reported (on a 9-pont scale) feeling more cooperative after reading the cooperation passage $(M=6.85)$ than after reading the control passage $(M=5.50)$, $t(23)=3.51, p=.002, d=1.46$. Our other cooperation-prime materials were piloted in a similar fashion. 
pants to help her out. The telephone call lasted approximately $1 \mathrm{~min}$, and afterward the experimenter resumed the study. On the basis of the findings of Chartrand and Bargh (1996), we anticipated that this more explicit goal manipulation would yield comparable effects to the other goal manipulations.

At the end of the experiment, participants completed a funnel debriefing. As noted earlier, 3 participants, all in the cell phone condition, reported suspicion of the goal manipulation and were excluded from the data set.

\section{Results}

Means on the sleep measure for Session 1 and Session 2 across the experimental conditions are displayed in Table 2. To test our hypotheses, we submitted these sleep data to a 2 (time) $\times 6$ (condition) mixed ANOVA. This analysis yielded a significant main effect for time, $F(1,113)=20.72, p<.001, \eta_{p}^{2}=.16$, indicating that, overall, participants reported sleeping better during the second session. It is important to note that this main effect was qualified by a significant Time $\times$ Condition interaction, $F(5$, $113)=4.26, p=.001, \eta_{p}^{2}=.16$. We again performed simple contrasts on the change in the pretest and posttest scores to test our predictions. We computed the change scores by subtracting scores on the Session 1 sleep index from scores on the Session 2 sleep index, so that higher numbers equated to increased placeboconsistent responding. First, a comparison between the notreatment condition $(M$ change $=0.06)$ and the no-expectation condition $(M$ change $=-0.01)$ yielded no significant effect $(p=$ .87 ), which suggests that simply engaging in the writing task did not alter participants' perceptions of their sleep quality. A comparison between the no-expectation condition and the placeboexpectation condition ( $M$ change $=0.02$ ) was also nonsignificant $(p=.95)$. This comparison indicates that, by itself, the placebo expectation did not alter how participants rated the quality of their sleep. In contrast, separate comparisons between participants in the no-expectation condition and those in story-prime condition $(M$ change $=0.88)$, the evening-prime condition $(M$ change $=1.09)$, and the cell phone condition $(M$ change $=1.49)$ all yielded significant effects, $t(113)=1.97, p=.05, d=0.61 ; t(113)=$ $2.44, p=.01, d=0.81$; and $t(113)=3.38, p=.001, d=1.25$, respectively. Comparisons between the placebo-expectation condition and each of the goal-prime conditions also yielded this same pattern of results ( $t \mathrm{~s} \geq 1.95, p \mathrm{~s} \leq .05, d \mathrm{~s} \geq 0.59$ ). Thus, participants followed the placebo expectation when the goal was activated by any of the three methods used in this experiment.

\section{Discussion}

Study 2 provides further support for the current motivation hypothesis and extends the findings of Study 1 in a number of important ways. First, rather than occurring briefly in the laboratory, the treatment in Study 2 took place outside of the laboratory and over a much longer span of time. Despite these changes, the same pattern of results emerged. Given the large number of factors that likely influence the sleeping habits of undergraduate students, these effects are quite striking. Another change from Study 1 is that the symptom domain was no longer diffuse positive affect but rather students' perceptions of their sleep quality. These data supply evidence for the hypothesis that motivation plays a role in an array of placebo symptoms. In Study 2 we also used three different goal activation techniques, and we found the enhancing effect for all three methods. It is interesting that this result appeared strong even when we used a more obvious goal prime. This finding may prove important to medical practitioners who are looking to generate placebo reactions (see Andrews, 2001).

Finally, the data also reveal that for goals to moderate the effects of placebo expectations, the goals do not have to be activated prior to the administration of the expectation. Instead, it appears that a goal can be activated much later and still alter placebo reactions. We suspect that as long as the goal is mentally associated with the placebo expectation, it will increase this effect. Further data are needed, however, to explore the temporal relation between goal activation and placebo expectations.

\section{Study 3}

In Study 3 we attempt to address three main issues. First, in the previous two experiments we did not include a condition in which participants were given a cooperation goal but were not given a placebo expectation. Because of this, it could be argued that the placebo effects observed in Studies 1 and 2 occurred solely because of the goal manipulation, not the combination of the cooperation goal and the placebo expectation. Therefore, Study 3 includes a condition in which participants received a cooperation goal but no placebo expectation.

Second, in the previous two experiments, participants received placebo expectations for positively valenced feeling states. In Study 3, we test whether goals can increase placebo responding even when the placebo expectation is to feel unpleasant symptoms. As stated earlier, we hypothesized that goals moderate both positive and negative placebo expectations.

Finally, we also conducted Study 3 to help rule out an alternative explanation that could be given for the results of Studies 1 and 2. Specifically, it could be argued that positive semantic associations with the cooperation-prime words used in the earlier studies cued positive responding from participants in the experimental context (cf. Pendry \& Carrick, 2001). This argument could be made because responding in a manner consistent with the placebo expectation in both studies equated to more positive responses. Although various aspects of the data from the two previous studies could be marshaled to counter this semantic-association explana-

Table 2

Pretest and Posttest Means on the Sleep Index for Study 2

\begin{tabular}{ccccccc}
\hline Test & $\begin{array}{c}\text { No } \\
\text { treatment }\end{array}$ & $\begin{array}{c}\text { No } \\
\text { expectation }\end{array}$ & $\begin{array}{c}\text { Placebo/ } \\
\text { expectation }\end{array}$ & $\begin{array}{c}\text { Story prime/ } \\
\text { expectation }\end{array}$ & $\begin{array}{c}\text { Evening prime/ } \\
\text { expectation }\end{array}$ & $\begin{array}{c}\text { Cell phone prime/ } \\
\text { expectation }\end{array}$ \\
\hline Pretest & 4.42 & 4.72 & 4.93 & 4.26 & 4.25 & 3.52 \\
Posttest & 4.48 & 4.71 & 4.95 & 5.14 & 5.34 & 5.01 \\
\hline
\end{tabular}

Note. Higher pretest and posttest scores indicate better quality of sleep. 
tion, we could accomplish a more direct test of this alternative hypothesis by having the placebo responses be negatively valenced. As noted above, this is exactly what we did in Study 3.

The design of Study 3 is in many ways similar to that of Study 2. We again had participants complete the sleep measure on two consecutive days and again asked them to perform the writing task before they went to bed. This time, however, the placebo expectation was that this task would make participants more mentally active and would disrupt their sleep. Orthogonal to this manipulation, half of the participants were primed with a cooperation goal, whereas the other half were not. It was predicted that the participants given the placebo expectation and the cooperation goal would be the most likely to exhibit the placebo effect.

\section{Method}

Participants and design. Fifty-nine female and 34 male psychology undergraduates participated (in small groups) in return for partial course credit. The data from 8 additional students who began the study are not included in the present analyses. Three participants failed to attend the second session of the study, and 2 participants reported that they did not complete the take-home portion of the study as instructed. The final 3 participants reported suffering from insomnia or other sleep disorders and were taking medication to help them sleep the night of the study.

Participants were randomly assigned to receive either a placebo expectation or no expectation and to receive either a goal prime or no goal prime. The overall design was a 2 (time) $\times 2$ (placebo expectation) $\times 2$ (goal prime) mixed design, with the first factor within subject and the latter two factors between subjects.

Procedure. The general procedure used in this study closely resembles that of Study 2. All participants attended two experimental sessions on consecutive weekdays in which they completed the same questionnaire packets handed out in Study 2. To manipulate placebo expectations, the experimenter told participants in the placebo-expectation condition that she was studying the potential negative consequences of mental activity right before bed. She explained that excessive thinking right before bed stimulates the brain and hinders one's sleep. These participants were told that the writing task would disrupt their sleep and lower their energy level on the following day. As in Study 2, the no-placebo expectation participants did the same writing task in the evening, although they were not given the expectation that the writing task would alter the quality of their sleep. To manipulate the goal of cooperation, we used the story-prime materials from Study 2. Specifically, half of the participants read the cooperation story used in Study 2, whereas the others read the control passage. At the end of Session 2, participants again took part in a funnel debriefing. None of the participants reported any awareness or suspicion that the passages they read could have altered their responses in the sleep portion of the study.

\section{Results}

Table 3 displays the means on the sleep index for both sessions

Table 3

Pretest and Posttest Means on the Sleep Index for Study 3

\begin{tabular}{ccccccc}
\hline & \multicolumn{2}{c}{ No prime } & & \multicolumn{2}{c}{ Cooperation prime } \\
\cline { 2 - 3 } \cline { 5 - 6 } Test & $\begin{array}{c}\text { No } \\
\text { expectation }\end{array}$ & $\begin{array}{c}\text { Negative } \\
\text { expectation }\end{array}$ & & $\begin{array}{c}\text { No } \\
\text { expectation }\end{array}$ & $\begin{array}{c}\text { Negative } \\
\text { expectation }\end{array}$ \\
\hline Pretest & 4.62 & 4.67 & & 4.61 & 4.60 \\
Posttest & 4.90 & 4.83 & & 5.03 & 3.87 \\
\hline
\end{tabular}

Note. Higher pretest and posttest scores indicate better quality of sleep. across the four experimental conditions. The sleep scores were submitted to a 2 (time) $\times 2$ (placebo expectation) $\times 2$ (goal prime) mixed ANOVA. This ANOVA produced a significant Session $\times$ Placebo Expectation interaction, $F(1,89)=6.15, p=.01, \eta_{p}^{2}=$ .07. This interaction indicates that the placebo-expectation participants reported experiencing more negative placebo symptoms in the second session than did the no-expectation participants. It is important to note that this ANOVA also yielded a significant Time $\times$ Expectation $\times$ Goal Prime interaction, $F(1,89)=4.14$, $p=.04, \eta_{p}^{2}=.04$. Simple contrasts were again performed on the change in participants' sleep scores, with, this time, lower numbers on the index equating to an increase in placebo-consistent responding. The first contrast revealed that, as predicted, when participants were primed with the goal of cooperation, there was a significant difference between the placebo-expectation participants $(M$ change $=-0.73)$ and the no-expectation participants $(M$ change $=$ $0.42), t(89)=3.20, p=.002, d=0.98$. However, no difference emerged between the placebo-expectation $(M$ change $=0.16)$ and the no-expectation participants $(M$ change $=0.27)$ when they were not primed for cooperation $(p=.75)$.

\section{Discussion}

The findings of Study 3 are again consistent with the hypothesis that nonconscious goals moderate the effects of placebo expectations. As in Study 2, this goal-priming effect was found in a lengthy experiment, with a large portion of the study occurring outside of the laboratory. It is important to note that these data indicate that the effects observed in the first two experiments can extend to situations in which individuals are given a negativeplacebo expectation. This finding suggests that a more motivational approach to the placebo effect can successfully account for placebo data in which expectations lead to unpleasant consequences. Also, these data demonstrate that the present effects are not just a result of positive semantic associations, with the cooperation prime cuing participants to make positive ratings. Finally, unlike the previous studies, Study 3 incorporates a condition in which participants were given the goal of cooperation but no placebo expectation. The results indicate that, at least in this context, the goal of cooperation alone does not result in increased placebo responding.

\section{Study 4}

We conducted Study 4 to assess two additional issues regarding the present findings. First, the placebo treatments in the prior three experiments were presumably novel to most of the participants. That is, the participants were likely unsure how the sleep or music therapy would really make them feel. It could be argued that goal manipulations will only increase the influence of placebo expectations when the exact treatment effects are ambiguous to participants. When the anticipated reactions are not novel or ambiguous, it could be that goals, such as to cooperate, are overridden by prior knowledge. To examine this possibility in Study 4, we had participants ingest placebo capsules that they were told contained caffeine. We used a caffeine placebo because caffeine is a drug that most undergraduate students have likely consumed in the past. This was confirmed in a small pilot study in which $87 \%$ of the undergraduate students sampled $(n=70)$ reported consuming at 
least one caffeinated beverage a day ( $M=2.30$ per day). Study 4 was designed to test whether the goal of cooperation would moderate placebo responding even when participants had prior experience with the placebo symptoms.

A second feature of Study 4 is that it includes dependent measures other than self-report. Although a great deal of the placebo literature uses self-report measures to assess placebo responding, some controlled studies report that placebo expectations can also alter responses on more objective measures (Kirsch \& Weixel, 1988). To test whether goals alter placebo responding on measures other than self-report, in Study 4 we recorded participants' blood pressure during a performance task. Because caffeine is a stimulant, it was predicted that elevations in blood pressure would be consistent with the placebo expectation. Therefore, participants given the goal prime and placebo expectation would expect to have elevated blood pressure. In addition, we videotaped participants' behavior in Study 4 and subsequently coded their actions for signs of increased arousal. Prior research has found that higher levels of arousal are associated with the nonverbal behaviors of self-touching, such as rubbing one's face, and the manipulation of objects, such as picking up a computer mouse (S. Duncan \& Fiske, 1977; Knapp \& Hall, 1992). On the basis of these findings, we recorded participants' self-touching actions and object manipulation actions in Study 4 as another indicator of placebo responding. We anticipated that the participants given the placebo expectation and the goal prime would make the most arousal-related actions. Finally, we also measured reaction times on several performance tasks to explore the possibility that our effects would extrapolate to changes in reaction time.

\section{Method}

Participants and design. Thirty-seven female and 20 male psychology undergraduates who were nonsmokers and who were not currently taking prescription medication participated in return for partial course credit. The data from 2 students who began the study are not included in the present analyses because 1 was not a native English speaker and did not understand the instructions and the 2 nd refused to ingest the placebo capsule. Finally, because of equipment malfunctions on 1 day of data collection, we do not have videotape data for 3 participants.

Participants were randomly assigned to one of four conditions, which resulted in a 2 (time) $\times 2$ (placebo expectation) $\times 2$ (goal prime) mixed design, with the first factor within subject and the latter two factors between subjects.

Procedure. On arrival, the no-expectation participants were told that the focus of the research project was to examine the relation between physiological reactions and performance on a visual perception task. Participants in the caffeine-expectation condition were told that the study was exploring the relations among caffeine, physiological reactions, and a visual performance task. Participants were then seated at a desk in front of a computer screen. A video camera was placed in an adjacent room connected by a one-way mirror to film participants from the waist up. All participants agreed to have their behavior videotaped prior to beginning the study.

Participants then completed a student lifestyle questionnaire on which they rated how frequently they performed a variety of behaviors on an average day (e.g., hours slept, meals eaten). Included in these questions was an item that asked how many caffeinated beverages participants consumed in a day. We asked this question to give us an estimate of participants' experience with caffeine. Next, participants completed a brief affect questionnaire, on which they rated their feelings (e.g., "blue," "grieving," "mad"). Embedded in this questionnaire were the following four critical caffeine-related items added to form a baseline caffeinesymptom index: "calm," "excited," "sluggish," and "drowsy" (rated from $1=$ very slightly to $5=$ extremely).

At this point, the experimenter placed a blood pressure cuff on the participants' nondominant arm. The blood pressure readings were obtained via a Suntech (Morrisville, NC) automatic digital monitor that was set to record blood pressure readings at 1-min intervals. Participants were told to clear their mind and to relax for a 5-min resting baseline period.

After the baseline readings were recorded, participants spent a few minutes becoming acquainted with the visual performance tasks that they were to encounter later in the study. The tasks, used to corroborate the cover story and to keep participants active during the experiment, involved participants responding to a series of reaction time trials. The first task they encountered was a modified version of the Stroop task in which the items randomly varied in their placement on the computer screen. The colors used in this modified Stroop were red, green, blue, and yellow. The practice session consisted of five Stroop items. Next, participants practiced for a second task we created in which they counted how many times the letter $E$ appeared on the computer screen while it was surrounded by distractor letters. Participants then completed five practice trials of this task. They made responses for both tasks by clicking a mouse button on the correct answer among various possibilities given at the bottom of the computer screen.

Next, participants in the placebo-expectation conditions were give a small cup of water and an orange and white placebo capsule (containing sucrose) that they were told contained $250 \mathrm{mg}$ caffeine. They were further told that ingesting the capsule was equivalent to drinking two to two and a half average-sized cups of coffee. Participants were told that it would take approximately $5 \mathrm{~min}$ before they would feel the full effect of the caffeine. During the intervening time, participants were asked to take part in a second baseline reading, described as a mental activity baseline. This second baseline was, in actuality, a 20-item Scrambled Sentence Test. As in Study 1, participants received either the cooperation or the no-prime version. The experimenter was blind to this manipulation. Participants in the no-expectation condition went directly from practicing the performance task to doing the Scrambled Sentence Test with no mention of the caffeine.

After the Scrambled Sentence Test was completed, participants began the computer task during which their blood pressure was recorded. This performance period was composed of two 5-min sessions and incorporated blocks of each of the two different performance tasks discussed above. During the break between the two sessions, the computer program stopped, and the experimenter returned and asked participants to complete the affect questionnaire from the beginning of the experiment. When finished, the participants resumed the computer task and blood pressure recording. After the task was complete, participants again filled out the affect questionnaire containing our caffeine-symptom items. ${ }^{2}$ Finally, in a funnel debriefing, no one reported suspicion or awareness that the scrambled sentences somehow affected his or her reactions later in the study.

\section{Results}

Self-report data. Preliminary analyses among the four caffeine symptom items revealed that the "calm" item was not significantly associated with the other three items on the pretest or the posttest. This item was consequently dropped from our analyses. Participants' scores on the remaining caffeine symptom items were reverse scored when necessary and averaged to create a composite

\footnotetext{
${ }^{2}$ Caffeine takes substantially longer to affect individuals than we led our participants to believe in Study 4. As the participants might have been aware of or at least suspected this, we focused our primary data analyses on the second set of the performance trials. Analyses performed on the first set of trials produced similar but statistically weaker findings.
} 
Table 4

Means on All Measures for Study 4

\begin{tabular}{|c|c|c|c|c|}
\hline \multirow[b]{2}{*}{ Measure } & \multicolumn{2}{|c|}{ No prime } & \multicolumn{2}{|c|}{ Cooperation prime } \\
\hline & $\begin{array}{c}\text { No } \\
\text { expectation }\end{array}$ & $\begin{array}{l}\text { Caffeine } \\
\text { expectation }\end{array}$ & $\begin{array}{c}\text { No } \\
\text { expectation }\end{array}$ & $\begin{array}{l}\text { Caffeine } \\
\text { expectation }\end{array}$ \\
\hline \multicolumn{5}{|l|}{ Caffeine symptoms index } \\
\hline Pretest & 3.20 & 3.40 & 3.20 & 3.51 \\
\hline Posttest & 3.42 & 3.73 & 3.24 & 4.10 \\
\hline \multicolumn{5}{|c|}{ Systolic blood pressure (mm Hg) } \\
\hline Pretest & 113.70 & 115.57 & 117.69 & 113.40 \\
\hline Posttest & 113.87 & 112.13 & 115.89 & 114.57 \\
\hline Anxious behavior index & 1.46 & 1.33 & 1.47 & 2.36 \\
\hline \multicolumn{5}{|l|}{ Stroop reaction times (ms) } \\
\hline Pretest & 1,533 & 1,492 & 1,501 & 1,660 \\
\hline Posttest & 1,227 & 1,337 & 1,290 & 1,270 \\
\hline
\end{tabular}

Note. Higher pretest and posttest caffeine symptom scores indicate more caffeine-related symptoms. Higher scores on the anxious behavior index indicate more anxiety-related behavior.

precaffeine symptom index $(\alpha=.71)$ and postcaffeine symptom index $(\alpha=.77)$. Higher numbers on both indices equate to more caffeine symptoms. Scores on these indices were submitted to a 2 (time) $\times 2$ (placebo expectation) $\times 2$ (goal prime) mixed ANOVA (see Table 4 for cell means). This ANOVA yielded a main effect of time, $F(1,53)=12.93, p<.001, \eta_{p}^{2}=.20$, and a main effect of the placebo expectation, $F(1,53)=4.60, p=.03, \eta_{p}^{2}=.08$. These findings indicate that participants reported more caffeine symptoms later in the experiment and that the placebo-expectation participants reported more caffeine symptoms than the noexpectation participants. This ANOVA also yielded a marginally significant Time $\times$ Placebo Expectation interaction, $F(1,53)=$ 3.94, $p=.05, \eta_{p}^{2}=.07$. To test our specific predictions, we performed a set of planned contrasts on the change in reported caffeine symptoms. An initial comparison revealed a greater increase in caffeine symptoms for the placebo-expectation participants $(M$ change $=0.59)$ than for the no-expectation participants ( $M$ change $=0.04$ ) when they were primed for cooperation, $t(53)=2.31, p=.02, d=0.99$. When participants were not primed for cooperation, there was no difference between the placebo-expectation $(M$ change $=0.33)$ and no-expectation conditions ( $M$ change $=0.22, p=.63$ ). When we included selfreported caffeine consumption in the analyses as a covariate, it was nonsignificant $(p s>.50)$. Also, including caffeine consumption as an independent variable in the analysis (on the basis of a median split) did not produce significant effects or alter the pattern of results. These findings provide further evidence that a lack of symptom familiarity is not responsible for the current findings. The same caffeine experience analyses were performed with the other dependent measures and did not produce significant results. Therefore, we do not discuss this variable further.

Blood pressure data. We then examined the results of the blood pressure data. To obtain a baseline systolic blood pressure score, we averaged together the last four of participants' five baseline systolic blood pressure readings. Next, we averaged together participants' systolic blood pressure readings during the second half of the performance task. ${ }^{3}$ These data were then submitted to a 2 (time) $\times 2$ (placebo expectation) $\times 2$ (goal prime) ANOVA. This ANOVA generated an effect of time, $F(1,50)=$
$3.80, p=.05, \eta_{p}^{2}=.07$, reflecting the finding that, overall, systolic blood pressure decreased during the study. This analysis also generated a significant three-way interaction, $F(1,50)=10.92$, $p=.002, \eta_{p}^{2}=.18$ (see Table 4). Simple contrasts on the change in systolic blood pressure revealed that, as anticipated, when given the goal of cooperation, the placebo-expectation participants $(M$ change $=1.17$ ) had a greater increase in systolic blood pressure than the no-expectation participants $(M$ change $=-1.80), t(50)=$ $2.11, p=.04, d=0.81$. A comparison between the placeboexpectation ( $M$ change $=-3.44)$ and no-expectation conditions ( $M$ change $=0.17)$ when participants were given no primes revealed that these conditions also differed, $t(50)=2.56, p=.01$, $d=1.07$. This difference, however, was in the opposite direction than was predicted and observed in the goal-prime conditions. Finally, similar analyses performed on diastolic blood pressure yielded no significant effects of our manipulations.

Behavioral coding data. To construct a behavioral measure of placebo reactions, we counted the number of self-touching actions and object manipulation actions made by our participants during a thin-slice section of the experiment. Specifically, we coded participants' behavior after they completed a questionnaire between the two blocks of performance trials. Three independent coders, blind to condition, viewed these video clips and counted the self-touching and object manipulation actions. The coders' ratings were averaged together $(\alpha=.83)$ to create a placebo-behavior index. Because scores on this index demonstrated a positive skew, we performed a square root transformation. This transformation was successful in normalizing the data. Then scores on this placebo-behavior index were submitted to a 2 (placebo expectation) $\times 2$ (goal prime) ANOVA. Although the pattern of means was in line with our predictions (see Table 4), the ANOVA did not yield any significant effects $(p s>.09)$. To test our specific predictions, we performed a set of planned contrasts (cf. Rosenthal

\footnotetext{
${ }^{3}$ To protect against noise and movement artifact, we omitted blood pressure scores when they were three standard deviations from the mean (Clark et al., 1987). This resulted in the loss of 3 participants' systolic blood pressure data.
} 
\& Rosnow, 1985). The first contrast, testing the difference between the goal-prime participants who were given the placebo expectation $(M=2.36)$ and those given no expectation $(M=$ 1.47), yielded the anticipated effect, $t(50)=2.09, p=.04, d=$ 0.87 . However, when this same comparison was performed for the no-prime participants, it was nonsignificant $(p=.77$; for the placebo-expectation condition, $M=1.33$; for the no-expectation condition, $M=1.46$ ). These data indicate that the expectation altered behavior only when participants were primed for cooperation.

Reaction time data. As mentioned earlier, we recorded how quickly participants responded in the visual performance trials. We incorporated these tasks in an effort to keep participants active and believing in the cover story. Nevertheless, we thought it would be informative to explore the reaction time data. Recall that one task was a variant of the Stroop test and that in the other task participants counted letters on the computer screen. When we examined the overall reaction times for both tasks, we found no significant effects associated with either of our independent variables ( $p \mathrm{~s}>$ .20). To further explore the reaction time data, we compared participants' reaction times on the first five items with their reaction times on the last five items for both tasks. This allowed us to examine the change in participants' reaction times. We submitted the reaction time data for each task to separate 2 (time) $\times 2$ (placebo expectation) $\times 2$ (goal prime) ANOVAs. The ANOVA performed on the Stroop data revealed a significant main effect of time, $F(1,53)=75.24, p<.001, \eta_{p}^{2}=.59$ (see Table 4), indicating that participants reacted more quickly during the later Stroop trials. The ANOVA also yielded a significant three-way interaction, $F(1,53)=7.22, p=.01, \eta_{p}^{2}=.12$. A comparison of the change in Stroop reaction times revealed that when participants were primed for cooperation, the reaction times of the placeboexpectation participants ( $M$ change $=-390 \mathrm{~ms}$ ) decreased more than those of the no-expectation participants $(M=-211 \mathrm{~ms})$, $t(53)=2.05, p=.04, d=0.77$. The reaction time change for the no-prime participants with the placebo expectation $(M=-155$ $\mathrm{ms})$ and with no expectation $(M=-306 \mathrm{~ms})$ were not significantly different $(p=.09)$. These data provide preliminary evidence that goal primes can influence placebo responding on a Stroop task. The same analysis for the counting task that we created did not, however, yield any significant effects associated with the two manipulations (all $p \mathrm{~s}>.15$ ). ${ }^{4}$

\section{Discussion}

The results of Study 4 indicate that the moderating effect of cooperation goals is not restricted to placebos that are novel to participants. Instead, when participants were familiar with the symptoms in question, the goal manipulation still increased the placebo responding of the expectation participants. The data supporting this effect were found on measures of self-reported symptoms, physiological changes, and behavioral reactions. Taken together, the findings provide converging evidence that the present effects are not limited to self-report instruments. We theorize that placebo effects occurred on the more objective measures because the goal-primed participants were nonconsciously working to achieve the goal of cooperation (cf. Bargh et al., 2001; Wegner et al., 2003). This led these participants to behave differently in the experiment and altered their physiological state, in an expectationfulfilling manner.

One unanticipated finding in Study 4 is that on several of our dependent measures the no-expectation/no-prime condition showed the closest resemblance to the placebo-expectation/prime condition. For example, whereas systolic blood pressure in the placeboexpectation/no-prime condition and the no-expectation/prime condition both substantially decreased throughout the experiment, the no-expectation/no-prime condition did not show this reduction. In fact, the change in blood pressure in this condition was significantly greater than that observed in the placebo-expectation/noprime condition. One plausible explanation for this outcome stems from the type of situation we created in Study 4. The experiment was presented to participants as a test of their visual abilities. This might have provoked some anxiety and increasing levels of uncertainty in the participants. This uncertainty might have been particularly high for the no-expectation/no-prime participants, as they were not provided additional information, such as a goal or an expectation, by which to help them structure or frame the experience. Thus, this effect may be a result of the ambiguity of this performance context (cf. Cioffi, 1991). This hypothesis is consistent with earlier studies showing that expectations can reduce distress when participants are performing challenging and unfamiliar tasks (e.g., Johnson, 1973). Important for the present discussion, a comparison between the placebo-expectation/prime participants and participants in the three other conditions indicated that the placebo-expectation/prime participants experienced a significantly greater increase in systolic blood pressure than the other participants in the study, $t(50)=2.45, p=.01, d=0.75$.

\section{Study 5}

In the previous experiments we found that priming a goal of cooperation can increase placebo responding. It is important to note, however, that these experiments revealed little evidence for placebo effects in the absence of the cooperation primes. It remains unclear, then, whether cooperation primes have an influence in a stronger placebo context. Thus, we conducted a final study to determine whether goal priming increases placebo responding beyond an existing placebo effect.

To test this possibility, we set up a situation in which the participants would likely want the placebo treatment to be successful. Participants took part in a bogus music therapy that purportedly reduced feelings of stress and negative affect in college students. We suspected that our student participants would, in general, want this therapy to be successful. In this study we also attempted to strengthen the placebo expectation manipulation. To

\footnotetext{
${ }^{4}$ In each study, we tested for gender effects. In no study did gender significantly qualify our findings. In Study 4 , gender did, however, affect several measures when it was added into our ANOVAs. Consistent with earlier research (Helfer \& McCubbin, 2001), men's systolic blood pressure $(M=121.23)$ was significantly higher than women's $(M=111.60)$, $t(52)=3.39, p=.001, d=1.01$. Also, the repeated measures ANOVA on self-reported caffeine symptoms produced a significant Gender $\times$ Expectation interaction, $F(1,49)=5.57, p=.02, \eta_{p}^{2}=.10$. This interaction reflects the finding that women reported experiencing more caffeine symptoms (on both the pretest and the posttest measures) in the placeboexpectation condition than men.
} 
this end, we selected a longer music stimulus than in our previous music therapy study (Study 1) and boosted the expectation manipulation by having both the experimenter and a confederate impart the expectation. Prior research indicates that having both an experimenter and a fellow student express a belief produces a particularly strong affective expectation (Geers \& Lassiter, 1999). On the basis of the reliable goal-priming effects found in the previous experiments, we anticipated that the primes would increase placebo responding even in this stronger placebo context. Thus, we predicted a linear pattern of results, with participants given a placebo expectation and a cooperation goal showing a larger placebo effect than those given a placebo expectation and no cooperation goal, and with the latter participants showing a larger placebo effect than those given no expectation and no goal.

\section{Method}

Participants and design. Thirty-five female and 24 male psychology undergraduates, participating in return for partial course credit, were randomly assigned to one of three experimental conditions: (a) no expectation/no prime, (b) placebo expectation/no prime, and (c) placebo expectation/cooperation prime. Participants also completed an affect measure at the beginning and end of the study, which resulted in a 2 (time) $\times 3$ (condition) mixed design. The data from 1 participant were not included because he reported being suspicious of the expectation manipulation.

Procedure. Participants first completed a brief questionnaire on which they rated their current affective state. Embedded in this questionnaire were the following five critical affect items used to create a preaffect index: "relaxed," "tense," "restless," "fearful," and "carefree." Responses to these items were reverse scored when needed and ranged from 1 = very slightly to $5=$ extremely.

Next, participants in the no-expectation condition and the placeboexpectation conditions were given different information about the study. Participants in the no-expectation condition were told the study concerned the assessment of music and the feelings students had when listening to different sounds. In contrast, participants in the placebo-expectation conditions were told the study concerned a new music therapy that could relax, soothe, and relieve stress. It was further noted that, in prior studies, this particular therapy was very effective with students who were experiencing stress and negative affect due to day-to-day hassles (e.g., studying for exams).

All participants were then given the student lifestyle questionnaire administered in Study 4. We gave participants this questionnaire to provide us with an opportunity to strengthen the placebo-expectation manipulation. Specifically, while the expectation participants were completing this survey, a confederate walked into the experiment room and began talking with the experimenter. The confederate followed a scripted conversation and pretended to be a student who had participated in the study earlier that day. The confederate told the experimenter that he was sorry to interrupt but that the music had really helped him relax. He then asked whether he could get a copy of the music to take home. The experimenter quickly wrote down some information for the confederate, and then the confederate departed. In the no-expectation condition, the confederate also interrupted the experiment, pretending to have participated in the study earlier that day. In this condition, however, the confederate said he had lost his notebook, asked whether the experimenter had found the notebook in the experiment room, and then, after not finding the notebook, departed.

When the student lifestyle questionnaire was completed, participants were given one of the two Scrambled Sentence Tests used in Study 4. Participants in the no-expectation and placebo-expectation/no-prime conditions were given the no-goal version, whereas participants in the placeboexpectation/cooperation-prime condition were given the cooperation-prime version. The experimenter was blind to this manipulation.
When participants had completed the Scrambled Sentence Test, the experimenter played the bogus therapy recording. The recording was a 7-min selection of ocean sounds. The experimenter left the room while the track played and returned when it ended. Participants were then given the affect questionnaire from the beginning of the study. The five critical items on the measure were rescored when needed and averaged together $(\alpha=$ .70) so that higher numbers equate to more positive feelings. Once finished, participants took part in a funnel debriefing. None of the participants reported suspicion of the priming task.

\section{Results}

The affect scores were submitted to a 2 (time) $\times 3$ (condition) mixed ANOVA (see Table 5 for cell means). This analysis yielded a significant main effect of time, $F(1,56)=23.03, p<.001, \eta_{p}^{2}$ $=.29$, indicating that, overall, participants reported experiencing more positive affect at the end of the experiment. It is important to note that the analysis also revealed a significant Time $\times$ Condition interaction, $F(2,56)=8.67, p<.001, \eta_{p}^{2}=.24$. To investigate this interaction, we performed simple contrasts on the change in participants' affect. As predicted, the placebo-expectation/noprime participants reported a greater increase in positive affect $(M$ change $=0.33)$ than participants given no expectation or prime $(M$ change $=-0.02), t(56)=2.02, p=.04, d=0.71$. This finding, in conjunction with the main effect of time, confirms that the placebo effect occurred even in the absence of the priming manipulation. To examine whether the cooperation primes further increased placebo responding, we conducted a second contrast to compare the two placebo-expectation conditions. As anticipated, this contrast revealed that the placebo-expectation/goal-prime participants reported a greater increase in positive affect $(M$ change $=$ 0.73 ) than the placebo-expectation/no-prime participants, $t(56)=$ $2.24, p=.03, d=0.74$

\section{Discussion}

In the first four experiments, little evidence was found for placebo effects in the absence of the cooperation primes. In Study 5 , we constructed a stronger placebo context and were able to produce the placebo effect without the introduction of the goal priming. The results indicate that, in addition to inducing placebo responding, cooperation primes also increase placebo responding when other contextual factors are present to invoke the placebo response. These data enhance the generalizability of this work by increasing the range of situations in which we know goal priming affects placebo responding.

\section{General Discussion}

The placebo effect is arguably the most widely known psychological phenomenon in Western society. Despite this status, rela-

Table 5

Pretest and Posttest Means on Affect Index for Study 5

\begin{tabular}{lccc}
\hline Test & $\begin{array}{c}\text { No expectation/ } \\
\text { no prime }\end{array}$ & $\begin{array}{c}\text { Expectation/ } \\
\text { no prime }\end{array}$ & $\begin{array}{c}\text { Expectation/ } \\
\text { cooperation } \\
\text { prime }\end{array}$ \\
\hline Pretest & 3.66 & 3.72 & 3.48 \\
Posttest & 3.64 & 4.05 & 4.21 \\
\hline
\end{tabular}

Note. Higher pretest and posttest scores indicate more positive affect. 
tively little is currently known about the psychological processes by which the effect occurs. The purpose of the present work is to clarify the contributions of motivational factors to the placebo effect. We have described five experiments indicating that the effect of placebo expectations is moderated by one's current goals. This moderating effect was shown across different domains of symptomatology, placebo expectations, and types of dependent measures. The effect was found via four different goal activation techniques and in brief and more long-term experiments. When participants were primed with a goal that could be met by confirmation of the placebo expectation, the placebo effect emerged. However, when participants were primed with an incompatible goal, no evidence for the placebo effect was found. Finally, when the expectation on its own did not generate a placebo effect, the cooperation primes evoked the placebo effect. When a placebo expectation did result in the placebo effect, the cooperation primes served to amplify the effect.

Although the present data may be at odds with theorizing in the placebo literature, they complement current research in social psychology. Social psychologists are once again emphasizing the role of motivation in human behavior and have demonstrated that nonconscious goals influence a great deal of social behavior (Bargh, 1997). The present studies can be viewed as providing a link between nonconscious goal research and medical research. These findings could lead to the testing of novel hypotheses, such as what role motivation plays in hypochondria, medical student syndrome, and decisions to take medication or seek health care.

\section{Nonconscious Goal Research}

These data add to the existing nonconscious goal literature in several important ways. For example, our results indicate that nonconscious goal manipulations not only impact social judgment and behavior but also influence somatic experience. Our findings also point to the relative strength of goal-priming manipulations by demonstrating that these manipulations are not always transient but can alter responses on dependent measures given 18 to $24 \mathrm{hr}$ later. This finding supports the position espoused by Bargh et al. (2001) that the responses made in automatic goal studies are not due to reflex habitual responses, as may be argued on the basis of behaviorist theories. Instead, the present data demonstrate that nonconscious goal manipulations influence responses over longer periods of time than would be anticipated by habitual reflexes.

Another interesting element of the present findings concerns the timing of the goal manipulations. In the majority of the nonconscious goal studies, goals are manipulated prior to the presentation of the means by which the goal is achieved (e.g., Bargh et al., 2001). In Study 2, however, we included a condition in which the goal to cooperate was primed after the expectation manipulation. In this condition, we found that, even though the goal was activated later, the goal still affected placebo responding. Comparable results have been reported by Kunda and Spencer (2003), who have demonstrated that nonconscious goals can alter responses even when they are activated after a means has been presented. For example, Kunda and Spencer reported that goals activated $10 \mathrm{~min}$ into a social interaction with an out-group member can still alter the judgments made about that individual. In the current studies, goals moderated the effects of placebo expectations regardless of whether the goal was activated before or after an expectation manipulation. In sum, these studies indicate that as long as a nonconscious goal is associated with a means while that means can still be carried out, the goal can influence subsequent cognition and behavior.

Although the present experiments indicate that nonconscious goals moderate the effects of placebo expectations, questions remain regarding the underlying mechanisms. Our view is that the cooperation primes influence how participants attend to, label, process, and recall their feeling states. Thus, we contend that the cooperation-prime participants engaged in a directional processing style that results in increased placebo responding (cf. Kunda, 1990). One pivotal aspect of this directional processing style may be an attentional bias toward information that is congruent with the placebo expectation. Data consistent with this hypothesis have been found in several recent studies showing that nonconscious goals alter attentional processes. For example, Ratcliff and Lassiter (2005) reported that nonconscious goals influence both the type and the amount of information individuals perceive when attending to another's ongoing behavior. Similarly, Moskowitz (2002) has found that nonconscious goals direct attention to goal-relevant items, even at a preconscious level. Although these studies are consistent with our directional-processing perspective, other mechanisms may be at work to produce placebo responding. For example, instead of directly altering the evaluation of internal sensations, the cooperation primes may actually alter participants' level of suggestibility, which, in turn, may increase confidence in the placebo expectation. At the moment, this type of suggestibility mechanism cannot be ruled out. It is possible that both these and other mechanisms are responsible for the effects we have observed. Given the numerous situations in which the placebo effect has been reported, it seems plausible that there are multiple pathways by which goals cause placebo responding.

\section{Placebo Effect Research}

In addition to accounting for the results of the current studies, this goal activation view may help address several unresolved issues in the placebo literature. For example, although expectations affect placebo responding, administration of a placebo expectation does not yield the placebo effect in every case (e.g., Walach et al., 2002). On the basis of the current goal activation framework, such null results could be due to the lack of a placebo-compatible goal. When a placebo-compatible goal is not associated with the placebo expectation, the expectation is unlikely to have strong effects. Such inconsistent effects of placebo expectations in this literature thus do not warrant a wholesale rejection of the expectancy perspective; rather, these data point to the need for a combined expectancy-goal approach, as suggested by the present research.

In Study 3 we found that negative placebo expectations can lead to increased reports of negative placebo symptoms when a compatible goal has been activated. The finding that negative placebo expectations can cause increased symptom reporting is consistent with earlier placebo studies (Shapiro \& Morris, 1978). However, placebo effect scholars have noted that positive placebo expectations generally have stronger effects than negative placebo expectations (Gibbons \& Gaeddert, 1984; Ross \& Olson, 1982). From our perspective, the reason that negative expectations are less influential is that in medical settings, individuals often hold goals that are compatible with positive placebo expectations, whereas 
they are less likely to hold goals that are compatible with negative placebo expectations. Also, because extremely negative expectations may evoke higher order goals that can override a goal to fulfill a negative expectation, negative placebo-compatible goals may be short lived in this context (Norman \& Shallice, 1986). Thus, a goal activation view can readily account for this pattern of data.

The present results also have implications for research on reverse placebo effects, originally derived from Schachter's (1964) attributional theory of emotion. In one classic study, Storms and Nisbett (1970) examined the attributional analysis of insomniacs, who feel anxious at bedtime. In this study, Storms and Nisbett found that insomniacs actually fell asleep faster when they were given a placebo pill that purportedly increased arousal. Storms and Nisbett theorized that because the insomniacs were told the placebo pill would be arousal inducing, they misattributed their bedtime arousal to the pill and consequently felt less distressed. These initial findings, however fascinating, were difficult to replicate. Researchers thus studied potential moderating variables. This subsequent work revealed that reverse placebo effects are likely to occur on secondary assessment measures (i.e., measures of participants' belief about their underlying condition), when the expected internal state is parallel to one's actual state, and when individuals are closely examining their internal feeling state and the cause of those feelings (J. W. Duncan \& Laird, 1980; Girodo, 1973; Ross \& Olson, 1981). On the basis of the present studies, we believe that in addition to moderating traditional placebo effects, nonconscious goals moderate reverse placebo effects. Specifically, when the above conditions are in place, a placebo-compatible goal should increase the examination of one's symptoms, resulting in larger reversals. Conversely, a placebo-incompatible goal should reduce attention to and processing of one's feeling state and consequently decrease the likelihood of reverse placebo effects.

Some important distinctions between the prior work on motivational explanations of the placebo effect and the present research should be noted. First, earlier motivational explanations of the placebo effect have typically conceptualized motivation as an impulse to act in a manner benefiting the individual (e.g., Kienle \& Kiene, 1997; Price et al., 1999). Our conceptualization of motivation can be seen as more basic; we see motivation from the standpoint of an impulse that leads one to a course of action, be it beneficial or not. As noted earlier, this conceptualization allows for an explanation of negative placebo responses in the context of our model (see Study 3). Second, motives can be seen as coming from either sources outside of the self (external motivation) or sources specific to the self (internal motivation). The prior work on motivational explanations of the placebo effect has considered both sources but has emphasized internal motives (e.g., Gibbons \& Gaeddert, 1984; Plotkin, 1985). The studies in the present article, conversely, primarily examine external motivation in that we primed the goal of cooperation. Thus, although we feel this model should apply equally to internal and external sources of motivation, we do not have the data to properly examine the role of internal motivation as of yet. We can speculate, on the basis of the tenets of our model, that such internal motivations yield similar, if not stronger, results. Because internal motives likely have a stronger connection to the self than external motives, we may find that they result in greater self-regulatory effort and, ultimately, stronger placebo effects.
Although in the present studies we focus on the goal of cooperation, we suspect that in everyday life many goals moderate the placebo effect. Placebo responding may be influenced by the goals that individuals bring with them to a medical or research setting and also by the goals primed by various environmental cues. For instance, encountering doctors, nurses, or medical devices or even considering one's current health status may evoke goals such as social inclusion, personal control, and a need to achieve. An interesting line of research is to investigate how and when goals are activated and pursued in both medical and nonmedical settings.

In the present studies, we used various priming techniques to increase participants' desire to cooperate and have contended that the priming effects occurred nonconsciously. We are using the term nonconscious here to mean that the primed participants were unaware that the priming materials affected their subsequent responses. Thus, participants consciously perceived the goal-priming stimuli and might have even thought about the concept of cooperation when, for example, they read the cooperation-related words in the Scrambled Sentence Test. However, we maintain that participants did not recognize the influence that these stimuli had on their reactions. Our belief that the goal priming occurred nonconsciously is supported by prior research in which similar supraliminal primes evoked goals below conscious awareness and by studies finding comparable results with supraliminal and subliminal priming techniques (e.g., Chartrand \& Bargh, 1996). This belief is further supported by our funnel debriefings. In these debriefings, we consistently found that our participants did not know the priming materials affected their subsequent reactions and did not report having a conscious desire to cooperate with the experimenter. On the basis of these responses, one could conclude that our participants were not consciously aware that the goal primes altered their reactions. This interpretation is consistent with the theorizing of Bargh (1997) and many others (e.g., Freud, 1901/1965; Weinberger \& McClelland, 1990) that goals can have strong causal effects without surfacing into consciousness. Because we primed goals supraliminally rather than subliminally (Bargh \& Chartrand, 2000), however, it could be that our participants were aware of our priming stimuli but chose not to acknowledge this during the funnel debriefings. Although this possibility exists, there are several aspects of our results that counter it. For example, from this demand perspective, one would anticipate that the independent primes in Study 1 would produce less placebo responding, which they did not. Also, this demand interpretation does not as readily account for the differences found with the physiological and nonverbal behavior measures in Study 4. Ultimately, it is important in future work to replicate our results via subliminal priming techniques to more conclusively demonstrate that these effects occur without conscious awareness.

\section{Concluding Remarks}

The goal activation view advanced in this article has proven useful in predicting the placebo effect in the present studies and in refuting the traditional criticisms leveled against motivationally tinged explanations for the placebo effect. This approach may lead to advances for health care practitioners as well as for medical researchers who have difficulty predicting the seemingly erratic data gathered from placebo control conditions in medical trials (Enserink, 1999). Nevertheless, our results represent only an initial 
step toward understanding the role of motivation in the placebo effect. For instance, in the present research we focus on temporarily activated goals and do not investigate participants' chronic goals. If chronic and temporary goals have similar effects on placebo responding, this could help resolve the inconsistencies that currently plague the individual differences-placebo literature (Ader, 2000; Geers et al., 2005). Additionally, although we have only tested this model using nonclinical samples, we anticipate that these findings will extrapolate to clinical samples. Indeed, because clinical samples are likely to be more invested in treatment studies, goals may even have a greater impact with such samples (Beecher, 1960; Jospe, 1978). As these limitations point out, further research incorporating no-placebo control conditions and manipulating motives is needed to increase our knowledge of the placebo effect.

\section{References}

Aarts, H., \& Dijksterhuis, A. (2000). Habits as knowledge structures: Automaticity in goal-directed behavior. Journal of Personality and Social Psychology, 78, 53-63.

Aarts, H., Gollwitzer, P. M., \& Hassin, R. R. (2004). Goal contagion: Perceiving is for pursuing. Journal of Personality and Social Psychology, 87, 23-37.

Ader, R. (1997). The role of conditioning in pharmacotherapy. In A. Harrington (Ed.), The placebo effect: An interdisciplinary exploration (pp. 138-165). Cambridge, MA: Harvard University Press.

Ader, R. (2000). True or false: The placebo effect as seen in drug studies is definitive proof that the mind can bring about clinically relevant changes in the body. Advances in Mind-Body Medicine, 16, 1-11.

Amanzio, M., \& Benedetti, F. (1999). Neuropharmacological dissection of placebo analgesia: Expectation-activated opioid systems versus conditioning-activated specific subsystems. Journal of Neuroscience, $19,484-494$

Anderson, D. B., \& Pennebaker, J. W. (1980). Pain and pleasure: Alternative interpretations for identical stimulation. European Journal of Social Psychology, 10, 207-212.

Andrews, G. (2001). Placebo response in depression: Bane of research, boon to therapy. British Journal of Psychiatry, 178, 192-194.

Bargh, J. A. (1990). Auto-motives: Preconscious determinants of social interaction. In E. T. Higgins \& R. M. Sorrentino (Eds.), Handbook of motivation and cognition (Vol. 2, pp. 93-110). New York: Guilford Press.

Bargh, J. A. (1997). The automaticity of everyday life. In R. S. Wyer Jr. (Ed.), The automaticity of everyday life: Advances in social cognition (Vol. 10, pp. 1-61). Mahwah, NJ: Erlbaum.

Bargh, J. A., \& Chartrand, T. L. (2000). The mind in the middle: A practical guide to priming and automaticity research. In H. T. Reis \& C. M. Judd (Eds.), Handbook of research methods in social and personality psychology (pp. 253-285). New York: Cambridge University Press.

Bargh, J. A., Gollwitzer, P. M., Lee-Chai, A., Barndollar, K., \& Tröetschel, R. (2001). The automated will: Nonconscious activation and pursuit of behavioral goals. Journal of Personality and Social Psychology, 81, 1014-1027.

Baumeister, R. F., \& Vohs, K. D. (2004). Handbook of self-regulation: Research, theory, and applications. New York: Guilford Press.

Beecher, H. K. (1960, July 8). Increased stress and effectiveness of placebos and "active" drugs. Science, 132, 91-92.

Bienenfeld, L., Frishman, W., \& Glasser, S. P. (1996). The placebo effect in cardiovascular disease. American Heart Journal, 132, 1207-1221.

Bierman, S. F. (2000). True or false: The placebo effect as seen in drug studies is definitive proof that the mind can bring about clinically relevant changes in the body: "Of course mental events affect physical events." Advances in Mind-Body Medicine, 16, 11-13.
Bootzin, R. R. (1985). The role of expectancy in behavior change. In L. White, B. Tursky, \& G. E. Schwartz (Eds.), Placebo: Theory, research, and mechanisms (pp. 196-210). New York: Guilford Press.

Brody, H. (1985). Placebo effect: An examination of Grubaum's definition. In L. White, B. Tursky, \& G. E. Schwartz (Eds.), Placebo: Theory, research, and mechanisms (pp. 237-254). New York: Guilford Press.

Brody, H., \& Brody, D. (2000). The placebo response. New York: HarperCollins.

Cameron, L. D., \& Leventhal, H. (2003). The self-regulation of health and illness behavior. New York: Routledge.

Carver, C., \& Scheier, M. F. (1981). Attention and self-regulation: A control-theory approach to human behavior. New York: SpringerVerlag.

Carver, C., \& Scheier, M. F. (1998). On the self-regulation of behavior. Cambridge, England: Cambridge University Press.

Chartrand, T. L., \& Bargh, J. A. (1996). Automatic activation of impression formation and memorization goals: Nonconscious goal priming reproduces effects of explicit task instructions. Journal of Personality and Social Psychology, 71, 464-478.

Cioffi, D. (1991). Beyond attentional strategies: A cognitive-perceptual model of somatic interpretation. Psychological Bulletin, 109, 25-41.

Clark, L. A., Denby, L., Pregibon, D., Harshfield, G. A., Pickering, T. G., Blank, S., \& Laragh, J. H. (1987). A data-based method for bivariate outlier detection: Application to automatic blood pressure recording devices. Psychophysiology, 24, 119-125.

de Jong, P. J., van Baast, R., Arntz, A., \& Merkelbach, H. (1996). The placebo effect in pain reduction: The influence of conditioning experiences and response expectancies. International Journal of Behavioral Medicine, 3, 14-29.

Dijksterhuis, A., \& van Knippenberg, A. (1998). The relation between perception and behavior or how to win a game of Trivial Pursuit. Journal of Personality and Social Psychology, 74, 865-877.

Dorland, W. A. (1901). The American illustrated medical dictionary (2nd ed.). Philadelphia: W. B. Saunders.

Duncan, J. W., \& Laird, J. D. (1980). Positive and reverse placebo effects as a function of differences in cues used in self-perception. Journal of Personality and Social Psychology, 39, 1024-1036.

Duncan, S., \& Fiske, D. W. (1977). Face-to-face interaction. Hillsdale, NJ: Erlbaum.

Enserink, M. (1999, April 9). Can the placebo be the cure? Science, 284, 238-240.

Epley, N., \& Gilovich, T. (1999). Just going along: Nonconscious priming and conformity to social pressure. Journal of Experimental Social Psychology, 35, 578-589.

Ernst, E., \& Resch, K. L. (1995). Concept of true and perceived placebo effects. British Journal of Medicine, 311, 551-553.

Fisher, S. (2000). Is there really a placebo effect, professor? Advances in Mind-Body Medicine, 16, 19-21.

Fitzsimons, G. M., \& Bargh, J. A. (2003). Thinking of you: Nonconscious pursuit of interpersonal goals associated with relationship partners. Journal of Personality and Social Psychology, 84, 148-163.

Flaten, M. A., \& Blumenthal, T. (1999). Caffeine-associated stimuli elicit conditioned responses: An experimental model of the placebo effect. Psychopharmacology, 145, 105-112.

Fox, J. (1803). A new medical dictionary. London: Darton and Harvey.

Freud, S. (1965). The psychopathology of everyday life (J. Strachey, Ed. \& Trans.). New York: Norton. (Original work published 1901)

Geers, A. L., Helfer, S. G., Kosbab, K., Weiland, P. E., \& Landry, S. J. (2005). Reconsidering the role of personality in placebo effects: Dispositional optimism, situational expectations, and the placebo response. Journal of Psychosomatic Research, 58, 121-127.

Geers, A. L., \& Lassiter, G. D. (1999). Affective expectations and information gain: Evidence for assimilation and contrast effects in affective experience. Journal of Experimental Social Psychology, 35, 394-413. 
Gibbons, F. X., \& Gaeddert, W. P. (1984). Focus of attention and placebo utility. Journal of Experimental Social Psychology, 20, 159-176.

Girodo, M. (1973). Film-induced arousal, information search, and the attribution process. Journal of Personality and Social Psychology, 25, 357-360.

Gross, J. J. (1998). The emerging field of emotion regulation: An integrative review. Review of General Psychology, 2, 271-299.

Hammersley, R., Finnigan, F., \& Millar, K. (1998). Verbal expectancies and performance after alcohol. Addictive Behaviors, 23, 489-496.

Harrington, A. (1997). The placebo effect: An interdisciplinary exploration. Cambridge, MA: Harvard University Press.

Harris, M. J. (1990). Effects of interaction goals on expectancy confirmation in a problem-solving context. Personality and Social Psychology Bulletin, 16, 521-530.

Hassin, R. R., \& Bargh, J. A. (2001). It takes two to tango: The therapist, the patient, and automatic aspects of their in-between. Psychological Inquiry, 12, 151-154.

Helfer, S. G., \& McCubbin, J. A. (2001). Does gender affect the relation between blood pressure and pain sensitivity? International Journal of Behavioral Medicine, 8, 220-229.

Hernstein, R. J. (1962, November 9). Placebo effect in the rat. Science, 138, 677-678.

Hilton, J. L., \& Darley, J. M. (1991). The effects of interaction goals on person perception. In M. P. Zanna (Ed.), Advances in experimental social psychology (Vol. 24, pp. 235-267). San Diego, CA: Academic Press.

Hróbjartsson, A. (1996). The uncontrollable placebo effect. European Journal of Clinical Pharmacology, 50, 345-348.

Hróbjartsson, A., \& Gotzsche, P. C. (2001). Is the placebo powerless? An analysis of clinical trials comparing placebo with no treatment. New England Journal of Medicine, 344, 1594-1601.

Jastrow, J. (1906). The subconscious. New York: Houghton Mifflin.

Jensen, M. P., \& Karoly, P. (1991). Motivational and expectancy factors in symptom perception: A laboratory study of the placebo effect. Psychosomatic Medicine, 53, 144-152.

Johnson, J. E. (1973). Effects of accurate expectations about sensations on the sensory and distress component of pain. Journal of Personality and Social Psychology, 27, 261-275.

Jospe, M. (1978). The placebo effect in healing. Lexington, MA: Lexington Books.

Kienle, G. S., \& Kiene, H. (1996). Placebo effect and placebo concept: A critical methodological and conceptual analysis of reports on the magnitude of the placebo effect. Alternative Therapies, 2, 39-54.

Kienle, G. S., \& Kiene, H. (1997). The powerful placebo: Fact or fiction? Journal of Clinical Epidemiology, 50, 1311-1318.

Kirsch, I. (1991). The placebo effect as a conditioned response: Failures of the "litmus test." Behavioral and Brain Sciences, 14, 200-201.

Kirsch, I. (1997). Specifying nonspecifics: Psychological mechanisms of placebo effects. In A. Harrington (Ed.), The placebo effect: An interdisciplinary exploration (pp. 166-186). Cambridge, MA: Harvard University Press.

Kirsch, I. (1999). How expectancies shape experience. Washington, DC: American Psychological Association.

Kirsch, I., \& Sapirstein, G. (1998, June). Listening to Prozac but hearing placebo: A meta-analysis of antidepressant medication. Prevention \& Treatment, 1, Article 0002a. Retrieved April 1, 2002, from http:// journals.apa.org/prevention/volume1/pre0010002a.html

Kirsch, I., \& Weixel, L. J. (1988). Double-blind versus deceptive administration of a placebo. Behavioral Neuroscience, 102, 319-323.

Knapp, M. L., \& Hall, J. A. (1992). Nonverbal communication in human interaction (3rd ed.). Fort Worth, TX: Harcourt Brace Jovanovich.

Kunda, Z. (1990). The case for motivated reasoning. Psychological Bulletin, 108, 480-498.

Kunda, Z., \& Spencer, S. J. (2003). When do stereotypes come to mind and when do they color judgment?: A goal-based theoretical framework for stereotype activation and application. Psychological Bulletin, 129, 522 544.

Lang, J. H. (1988). Larousse gastronomique: The new American edition of the world's greatest culinary encyclopedia. New York: Crown.

Lansky, P. (1994). Three moves for marimba [Recorded by N. Zettsman]. On See ya Thursday [CD]. Lisboa, Portugal: Equilibrium. (1999).

Lasagna, L. (1986). The placebo effect. Journal of Allergy and Clinical Immunology, 78, 161-165.

Laska, E., \& Sunshine, A. (1973). Anticipation of analgesia: A placebo effect. Headache, 1, 1-11.

Lazarus, R. S., \& Folkman, S. (1984). Stress, appraisal, and coping. New York: Springer.

Lewis, C. T. (1953). A Latin dictionary. Oxford, England: Clarendon Press.

Macrae, C. N., \& Johnston, L. (1998). Help, I need somebody: Automatic action and inaction. Social Cognition, 4, 400-417.

Major, H. (1954). A history of medicine (Vol. 1.). Springfield, IL: Charles C. Thomas.

Margo, C. E. (1999). The placebo effect. Survey of Ophthalmology, 44, $31-44$.

McDonald, D., Mazzuca, S., \& McCabe, G. P. (1983). How much of the placebo "effect" is really statistical regression? Statistics in Medicine, 2, 417-427.

Miller, G. A., Galanter, E., \& Pribram, K. H. (1960). Plans and the structure of behavior. New York: Holt, Rinehart, \& Winston.

Moerman, D. (2002). Meaning, medicine, and the "placebo effect." Cambridge, England: Cambridge University Press.

Montgomery, G. H., \& Kirsch, I. (1996). Mechanisms of placebo pain reduction: An empirical investigation. Psychological Science, 7, 174176.

Moskowitz, G. B. (2002). Preconscious effects of temporary goals on attention. Journal of Experimental Social Psychology, 38, 397-404.

Neuberg, S. L. (1996). Expectancy influences in social interaction: The moderating role of social goals. In P. M. Gollwitzer \& J. A. Bargh (Eds.), The psychology of action: Linking cognition and motivation to behavior (pp. 529-552). New York: Guilford Press.

Norman, D. A., \& Shallice, T. (1986). Attention to action: Willed and automatic control of behavior. In R. J. Davidson, G. E. Schwartz, \& D. Shapiro (Eds.), Consciousness and self-regulation: Advances in research and theory (Vol. 4, pp. 1-18). New York: Plenum Press.

Olson, J. M., Roese, N. J., \& Zanna, M. P. (1996). Expectancies. In E. T. Higgins \& A. W. Kruglanski (Eds.), Social psychology: Handbook of basic principles (pp. 211-238). New York: Guilford Press.

Orne, M. T. (1962). On the social psychology of the psychological experiment, with particular reference to demand characteristics and their implications. American Psychologist, 17, 776-783.

Pendry, L., \& Carrick, R. (2001). Doing what the mob do: Priming effects on conformity. European Journal of Social Psychology, 31, 83-92.

Pennebaker, J. W., \& Skelton, J. A. (1981). Selective monitoring of physical sensations. Journal of Personality and Social Psychology, 41, 213-223.

Peters, D. (2001). Understanding the placebo effect in complementary medicine. London: Harcourt.

Plotkin, W. B. (1985). A psychological approach to placebo: The role of faith in therapy and treatment. In L. White, B. Tursky, \& G. E. Schwartz (Eds.), Placebo: Theory, research, and mechanisms (pp. 237-254). New York: Guilford Press.

Price, D. D., \& Fields, H. L. (1997). The contribution of desire and expectation to placebo analgesia: Implications for new research strategies. In A. Harrington (Ed.), The placebo effect: An interdisciplinary exploration (pp. 93-116). Cambridge, MA: Harvard University Press.

Price, D. D., Millings, L. S., Kirsch, I., Duff, A., Montgomery, G. H., \& Nicholls, S. S. (1999). An analysis of factors that contribute to the 
magnitude of placebo analgesia in an experimental paradigm. Pain, 83, $147-156$.

Ratcliff, J., \& Lassiter, G. D. (2005). Nonconscious goals and the perception of on-going behavior. Manuscript submitted for publication.

Rickels, K., Lipman, R., \& Raab, E. (1966). Previous medication, duration of illness, and placebo response. Journal of Nervous and Mental Disease, 142, 548-554.

Rosenthal, R., \& Rosnow, R. L. (1985). Contrast analysis: Focused comparisons in the analysis of variance. Cambridge, England: Cambridge University Press.

Ross, M., \& Olson, J. M. (1981). An expectancy-attribution model of the effects of placebos. Psychological Review, 88, 408-437.

Ross, M., \& Olson, J. M. (1982). Placebo effects in medical research and practice. In J. R. Eiser (Ed.), Social psychology and behavioral medicine (pp. 441-458). New York: Wiley.

Russell, J. A. (2003). Core affect and the psychological construction of emotion. Psychological Review, 110, 145-172.

Schachter, S. (1964). The interaction of cognitive and physiological determinants of emotional states. In L. Berkowitz (Ed.), Advances in experimental social psychology (Vol. 1, pp. 49-80). New York: Academic Press.

Shah, J. Y., \& Kruglanski, A. W. (2003). When opportunity knocks: Bottom-up priming of goals by means and its effects on self-regulation. Journal of Personality and Social Psychology, 84, 1109-1122.

Shah, J. Y., Kruglanski, A. W., \& Friedman, R. (2003). Goal systems theory: Integrating the cognitive and motivational aspects of selfregulation. In S. J. Spencer, S. Fein, M. P., \& J. M. Olson (Eds.), Motivated social perception: The Ontario symposium (Vol. 9, pp. 247275). Mahwah, NJ: Erlbaum.

Shapiro, A. K. (1964). A historic and heuristic definition of the placebo. Psychiatry, 27, 52-58.

Shapiro, A. K., \& Morris, L. A. (1978). The placebo effect in medical and psychological therapies. In S. Garfield \& A. Bergins (Eds.), Handbook of psychotherapy and behavior change: An empirical analysis (2nd ed., pp. 477-536). New York: Aldine.

Shapiro, A. K., \& Shapiro, E. (1997). The powerful placebo effect. Baltimore: John Hopkins University Press.

Snyder, M. (1992). Motivational foundations of behavioral confirmation. In M. P. Zanna (Ed.), Advances in experimental social psychology (Vol. 25, pp. 67-114). San Diego, CA: Academic Press.
Spiro, H. M. (1986). Doctors, patients, and placebos. New Haven, CT: Yale University Press.

Srull, T. K., \& Wyer, R. S. (1979). The role of category accessibility in the interpretation of information about persons: Some determinants and implications. Journal of Personality and Social Psychology, 37, 16601672.

Stewart-Williams, S. (2004). The placebo puzzle: Putting together the pieces. Health Psychology, 23, 198-206.

Stewart-Williams, S., \& Podd, J. (2004). The placebo effect: Dissolving the expectancy versus conditioning debate. Psychological Bulletin, 130, $324-340$.

Storms, M. D., \& Nisbett, R. E. (1970). Insomnia and the attribution process. Journal of Personality and Social Psychology, 16, 319-328.

Vase, L., Riley, J. L., \& Price, D. D. (2002). A comparison of placebo effects in clinical analgesic trials versus studies of placebo analgesia. Pain, 99, 443-452.

Voudouris, N. J., Peck, C. L., \& Coleman, G. (1985). Conditioned placebo responses. Journal of Personality and Social Psychology, 48, 47-53.

Walach, H., Schmidt, S., Dirhold, T., \& Nosch, S. (2002). The effects of a caffeine placebo and suggestion on blood pressure, heart rate, wellbeing, and cognitive performance. International Journal of Psychophysiology, 43, 247-260.

Wegner, D. M., Fuller, V., \& Sparrow, B. (2003). Clever hands: Uncontrolled intelligence in facilitated communication. Journal of Personality and Social Psychology, 85, 5-19.

Weinberger, J., \& McClelland, D. C. (1990). Cognitive versus traditional motivational models: Irreconcilable or complementary? In E. T. Higgins \& R. M. Sorrentino (Eds.), Handbook of motivation and cognition (Vol. 2, pp. 562-597). New York: Guilford Press.

White, L., Tursky, B., \& Schwartz, G. (1985). Placebo: Theory, research, and mechanisms. New York: Guilford Press.

Wickramasekera, I. (1985). A conditioned response model of the placebo effect: Predictions from the model. In L. White, B. Tursky, \& G. E. Schwartz (Eds.), Placebo: Theory, research, and mechanisms (pp. 255287). New York: Guilford Press.

Received April 26, 2004

Revision received April 12, 2005

Accepted April 19, 2005

\section{Instructions to Authors}

For Instructions to Authors, please visit www.apa.org/journals/psp and click on the "Instructions to Authors" link in the Journal Info box on the right. 